\title{
A STUDY OF ULTRASTRUCTURE OF EGG SHELL OF SCHISTOSOMA JAPONICUM
}

\author{
I. Transmission Electron Microscopic Observation \\ of S. japonicum Egg.
}

CAO HAN-MIN, WANG YUN-FANG and LONG SO*

SUMMARY. Ultrathin sections of egg shell of S. Japonicum were observed. The micropores and network of microcanals were first reported in egg shell of $S$. japonicum. Both the micropores and microcanals are lined by a membrane being continous with the inner layer of egg shell and filled with materials coming fron inside of the egg.

As in the egg of $S$. mansoni, the possibility of micropores and microcanals that may play an important role as natural channels in secreting materials such as soluble antigens and histolytic enzymes... etc., is discussed.

\section{Étude de l'ultrastructure de la coquille de l'œuf de Schistosoma japonicum}

RÉSUMÉ. Des sections ultrafines de la coquille sont étudiées. Les micropores et le réseau des microcanaux ont d'abord été observés dans la coquille. Les micropores et microcanaux sont tapissés par une membrane en continuité avec la paroi interne de la coquille et remplis de matériaux provenant de l'intérieur de l'œuf.

Comme dans l'œuf de $S$. mansoni, la possibilité que ces micropores et micro-canaux jouent un rôle important de voies naturelles en sécrétant des substances telles que des antigènes solubles, des enzymes histolytiques, etc., est discutée.

\section{Introduction}

Male and female adults of Schistosoma japonicum mate in mesenteric veins of human or animal hosts and lay eggs there. Some of the eggs go through intestinal wall, damage host tissue, and come into intestinal cavity, then being discharged with their host's feces. Other eggs are deposited in host tissues of liver and intestinal wall, causing granulomatous lesion. The egg shell in host tissue thus become

\footnotetext{
* Department of Biology, East China Normal University, Shanghai, China.
}

Accepté le 16 décembre 1981 . 
a natural interface of ecological association between egg embryo (or miracidium) and its surrounding host tissue. Therefore, the study on ultrastructures of egg shell is of great significance in further elucidate the morphology and physiology of schistosome egg and pathology of schistosomiasis, and its immunological mechanisms.

\section{Material and methods}

Eggs from liver tissue of rabbits artificially infected with Schistosoma (liver egg) and eggs from uterus of female schistosoma (uterus egg) were studied.

A definite quantity of cercariae of Chinese (mainland) strain of S. japonicum were inoculated to abdominal skin of a rabbit, which was killed 42-45 days later. Adult schistosoma were collected by perfusion method, and washed sufficiently with saline. Then, the uterus segments of female schistosoma were carefully cut down. Rabbit liver were taken out simultaneously, homogenized, and purified. Fresh living schistosome eggs were isolated by centrifugation. Specimen of uterus and eggs were pre-fixed for $3 \mathrm{hr}$. $\left(4^{\circ} \mathrm{C}\right)$ with $4 \%$ paraformaldehyde, buffered with $0.2 \mathrm{M}$ collidin ( $\mathrm{pH} 7.4$ ). postfixed in $1.7 \% \mathrm{OsO}_{4}$ solution (containing $0.04 \mathrm{~g} / \mathrm{ml}$ sucrose) with the same buffer for $45 \mathrm{~min}$, dehydrated through a series of graded ethanol and acetone, embeded in 618 epoxyresin. Ultramicrotomic sections were double stained with uranium acetate and lead citrate, examine by DXA -10 TEM.

\section{Results}

1 - Egg shells are composed of two (inner and outer) continuous layers of different electronic density. A thin inner layer of higher electronic density; and a thick, homogeneous outer layer with moderate electronic density. They are in close contact with each other. The total thickness of liver egg shells in average is $0.7 \mu$, while that of outer and inner layer is $0.67 \mu$ and $0.04 \mu$ respectively. There's no apparent statistical differences between total thickness of liver egg shells and that of uterus egg shells.

2 - Bristle-like short microspicules densely covered egg shell surface, estimated 300 microspicules per $\mu^{2}$. Their bases are continuous with outer shell layer, showing same electronic density. Microspicules of uterus egg shell are more regular in length, with pointed distal ends ( fig. 1), while that of liver egg shell are comparatively round and blunt, with average length $0.07 \mu$, average basal dia. $0.038 \mu$. Certain electronic dense substances often attached to their distal ends or between these microspicules (fig. 2). Sometimes, even make them difficult to be recognized.

In addition to the above mentioned numerous short microspicules which are predominantly covering shell surface, there also exists a few long microspicules with same electronic density as that of short ones; with average length $0.88 \mu, 12$ times as that of short ones. They are often slanting and curving at their distal ends, and without any regular distributive patterns (fig. 3). 

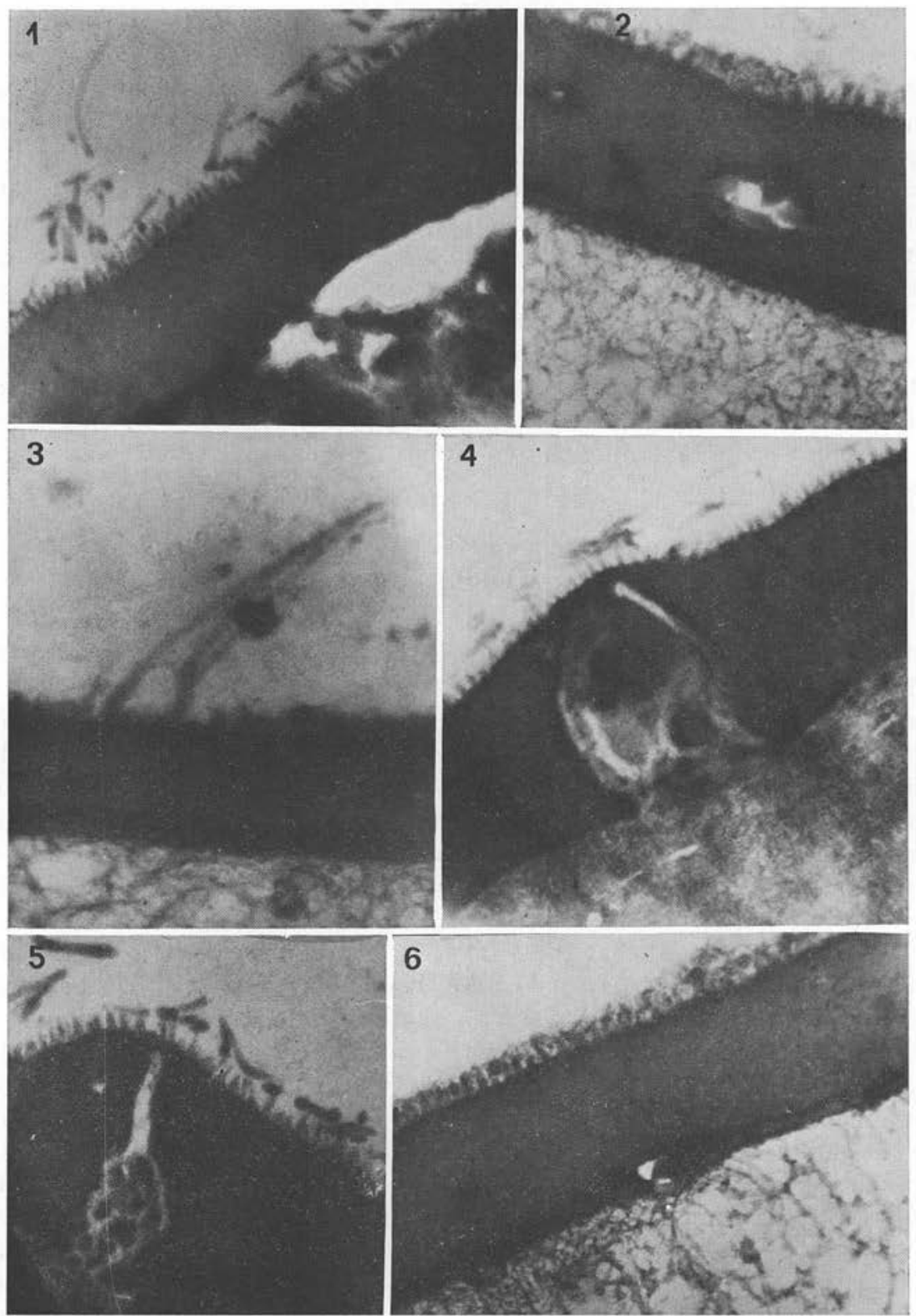

FIG. I to 5 .

Fig. I. - The microspicules on the egg shell in uterus. $38600 \mathrm{x}$. Fig. 2. - The short microspicules on the surface of liver egg shell. $62600 \mathrm{x}$. Fig. 3. - The long microspicules on the egg shell surface. $51000 \times$. Fig. 4. 5. - The micropore in the egg shell layer. $46000 \mathrm{x}, 54000 \mathrm{x}$.

FIG. 2 to 6 . - The cross sections of the microcanals existing in various spacing of egg shell layer. $62600 \mathrm{x}, 48000 \mathrm{x}$. 
3 - TEM observations show that micropores are scattered on shell surface. They are extended from inner parts of egg shells and directly go to outer surface. Egg shells are distinctively thickened around the micropores. Outer side dia., of a shell micropore is much smaller than its inner side dia., $0.06-0.12 \mu$ and $0.16-0.53 \mu$ respectively. The middle part of these pot-shaped shell micropores are larger, with dia. 0.33-0.64 $\mu$. These shell micropores are lined with a layer of membraneous structure of same electronic density as that of inner shell layer, and continuous with that layer. Thus, they possess a clear-cut border line from their neighbouring parts. These micropores are filled with substances apparently continuous with those inside the egg and with same electronic staining nature (fig. 4, 5).

Besides, there are crose sections of microcanals of various spacing. These sections are comparatively regularly shaped, near oval, with long axis parallel to shell surface. Its average size is $0,26 \times 0.12 \mu$, and contains substances of same electronic density to that of inside the egg shell. They are lined with and electronic dense membrane all around (fig. 6).

\section{Discussion}

Ultrastructure of egg shell in three species of Schistosoma, as well as the observation results of egg shell ultrastructure of S. japonicum by various authors (Table I, 2) are compared. From table $I$, there are quite a difference between the observations of various authors. It seems that there is quite a range of variation on the distributive density of microspicules on egg shell surface of S. japonicum. Table II shows that there are densely distributed short microspicules on the shell surface of all three Schistosoma species, and those of S. japonicum are much denser and shorter than those of other two species. Besides, there are a few curve-shaped long microspicules distributed among short ones.

It should be noticed that the scatteredly distributed microporous and microcanalar structures are first reported on egg shells of $S$. japonicum. The longitudinal section of a micropore indicates distinctly that it comes from inside of the egg shell and goes directly to shell surface. Its shape is somewhat different to the micropores on $S$. mansoni egg shell reported by Race $(1969,1971)$. The former are narrower at two ends and broader in the middle, with average dia. $0.31 \mu$; while the later become narrower and narrower from inside to outside, with smallest dia. $0.1 \mu$. But both of them are lined up with membraneous structures continuous to the inner shell layer, and both of them are filled with substances from inside of the egg shell.

The shape of cross sections of microcanals are rather regular. Most of them are oval, surrounded by electronic dense membranous linning, and filled with substances of same electronic density as those located inside the egg. Figure 7 shows how inside egg substances goes into the opening of microcanals, and how microcanals connected with inner egg shell. It seems that the inner wall of microcanals is an extension of inner shell layer. Besides, as cross sections of microcanals appear in different shell layers, from inside toward outside, in randomly cut ultramicrotomic sections ( $\mathrm{fig}$. 2, 
ULTRASTRUCTURE OF EGG SHELL OF SCHISTOSOMA

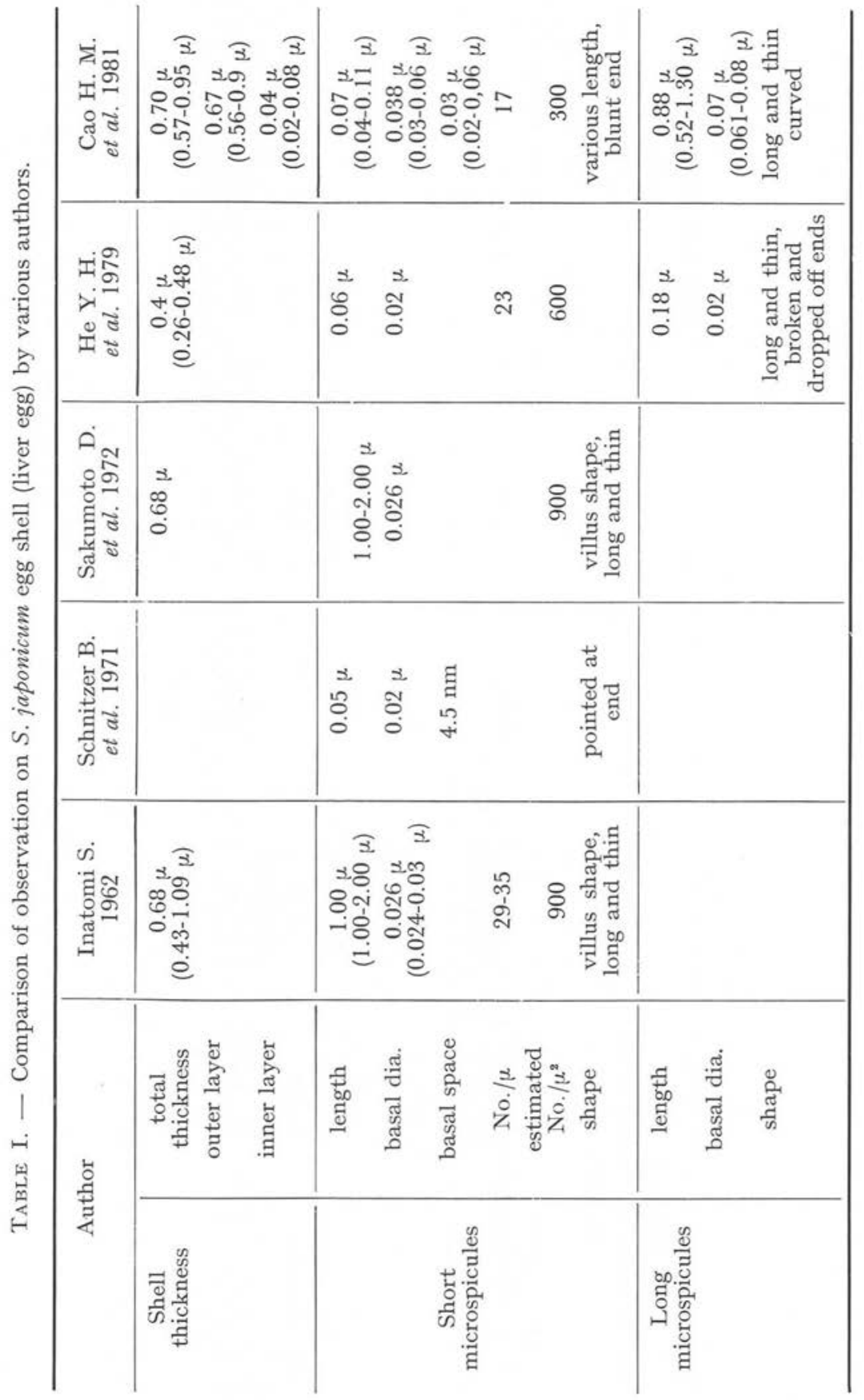




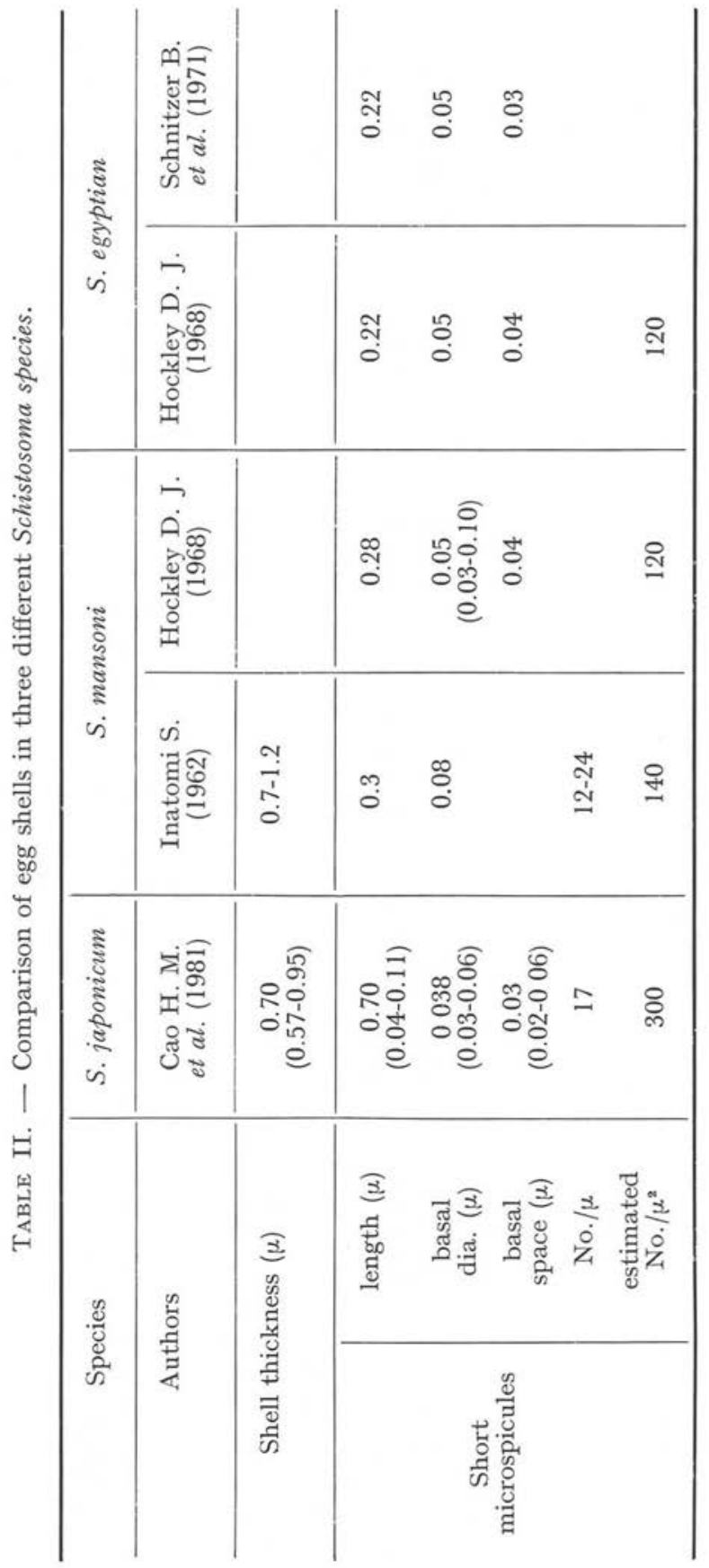


6 ); it seems that the microcanals within egg shell may be of various directions and with certain length. Furthermore, from above mentioned similarities of structures and inclusions of micropores and microcanals, it seems that there may be some developmental and functional consistencies between them.

According to above mentioned observations, the functions of egg shell may be further elucidated. In addition to the increasing of surface area, microspicules of shell surface may, help the egg to attach on inner wall of veinlets, and to avoid being washed away by blood streams. It also damages the endothelial cells of blood vessels and causes endophlebitis. Besides, the secreted substances from schistosome egg (include soluble antigens, histolytic enzymes... etc.) may be held close to its shell surface, in order to be fully utilized to react with neighbouring tissue. The electronic dense substances between microspicules (fig. 2) might be these secretions. It was reported that host immuno-globulin increases during egg laying stage of its parasitic schistosoma (Smithers et al., 1961). Again, Freeman et al. (1970) suggested that most of the antigens at that moment are non-specific, but some specific antigens also increase. This indicates that the egg is the strong antigenic stage in schistosome life cycle. Race et al. $(1969,1971)$ reported micropores on egg shell of $S$. mansoni, and suggested that the substances secreted by mature miracidium inside the egg, flowed out through micropores, are the antigen substances that induce delayed anaphylatic reactions. Recently, Tsiquaye et al. (1980) reported that primary cultures of human embryo liver cells have been found to be susceptible to the cytotoxic action of secretory products of living S. mansoni eggs. It is discovered in this investigation that in addition to similar micropores as mentioned above in egg shell of S. japonicum, there also exists microcanalar structures. It seems that in addition to the osmosis through egg shell, exchanges of substances on both sides of egg shell can also be performed through micropores and microcanals in shell layers. As the later are natural pathways, it will be likely to be more efficient than the former mech nism. The precipitations were caused by contact of mature schistosome eggs with immunoglobulin formed simultaneously on both sides (inner and outer) of egg shell (Sakumoto et al., 1972). Probably, this is the very result of mutual actions between antigen and antibody substances going through the above mentioned pathways.

\section{REFERENCES}

I. HE Y. H. et al., Scanning and transmission electron microscopy of Schistosoma japonicum egg shell. Chin Med. J., 1980, 93, 861-864.

2. FreEMAN et al., Specificity of immuno-globulin G in rhesus monkeys infected with Schistosoma mansoni, Plasmodium knowlesi and Trypanosoma brucei. J. Infec. Dis. I970, I21, 401.

3. Hockley D. J., Small spines on the egg shell of schistosoma. Parasitology, 1968, s8, 367-370.

4. Inatomi S., Submicroscopic structure of the egg shell of helminth. Okayama Igakkai Zasshi, I962, 74 (supplement), 31.

5. RAce G. J. et al., Schistosoma mansoni eggs : An electron microscopic study of shell pores and microbarbs. Proc. Soc. Expl. Biol. Med. 1969, 130, 990.

6. RACE G. J. et al., Scanning and transmission electron microscopy of Schistosoma mansoni eggs, cercariae and adults. Am. J. Trop. Med. Hyg., I971, 20, 9r4. 
7. SAKumoto K. et al. Ultrastructural observations of the circumoval precipitation of Schistosoma japonicum. In : Muneo Yokogawa (Ed.) Research in Filariasis and Schistosomiasis, Vol. 2, pp. 199-209. University of Tokyo Press, Tokyo, 1972.

8. Schnitzer B. et al., Microspines on Schistosoma japonicum and S. haematobium egg shells. Parasitology 62, 1971, 385-387.

9. Smithers S. R. et al., Serum protein changes in monkeys infected with Schistosoma mansoni, with special reference to the metabolism of albumin. Exp. Parasit. I961, II, 39.

ro. TsiguAYE K. N. et al., Cytotoxity of secretory product(s) of $S$. mansoni eggs in primary cultures of human embryo liver cells. In: Adeto Kumbo, O. Lucas (Ed.) The in vitro Cultivation of the Pathogens of Tropical Diseases, p. 36r, r980. 